\section{ALBUMINURIC RETINITIS.}

\section{BY SAMUEL WEST, M.D. OXON., F.R.C.P. LOND.,} ASSISTANT PHYSTCIAN TO ST. BARTHOLOMEW'S HOSPITAL.

IN its typical form albuminuric retinitis is characteristic and pathognomonic, yet upon many important points the statements of different authorities are very conflicting and difficult to reconcile. Kidney diseases fall into two great groups according as dropsy is a prominent symptom or not, and the kind of albuminuric retinitis most frequently met with in these two groups will, I think, be found to be different. The lesions of albuminuric retinitis consist in white patches, in hæmorrhages, and exudation variously combined with each other, and, lastly, in quasi-inflammatory conditions.

The exudative (inflammatory, extreme) torm. - In this form the changes are widespread and extreme, and closely resemble what is seen in other forms of acute neuro-retinitis. Dropsy is not very common in granular kidney, so this form of albuminuric retinitis but rarely occurs in this disease, but is more frequently met with in the other group-viz., in that of parenchymatous nephritis. Complicated as the question is we seem to be justified in drawing these conclusions-that this form of albuminuric retinitis is of an exudative inHammatory type, that it is probably of toxic origin, and that it is related rather to the cellular degeneration than to the interstitial fibrosis. If the view which I am expressing prove to be correct it follows not only that the kind of albuminuric retinitis which prevails in the two forms of renal disease is different, but that it has a different diagnostic value in the two cases. In parenchymatous nephritis the diagnosis of the disease is obvious and the albuminuric retinitis is an interesting by-phenomenon only. In granular kidney the diagnosis may be uncertain until all doubt is dispelled by the discovery of the characteristic eyechanges. It is to this group that some of the cases of albuminuric retinitis of pregnancy belong. On the other hand, many more of these cases in pregnancy belong to the degenerative group and are evidence of granular kidney. Puerperal eclampsia occurs in either form-in the former rarely without dropsy and in the latter not infrequently without.

The degenerative form of albuminuric retinitis consists in white patches and hæmorrhages. Of these the most characteristic are the white patches. There are, I believe, two kinds of white spots, the one forming bright spots glistening like fish scales, the other not so glistening or so sharply defined but woolly in appearance. The former are the result of degenerative changes and their brilliancy depends upon the presence of minutely refractive oildrops or even cholesterine crystals ; the latter are often small patches of exudation only. The former are of slow development and unlikely to disappear at all or only slowly and after a long time; the latter, however, may come and go rapidly. In parenchymatous nephritis the diagnosis of renal disease is usually obvious whether there be white spots or not. In granular kidney, however, the diagnosis may be uncertain until the eye-changes are discovered. The white spots, whether they be really exu. dative or degenerative, have therefore in granular kidney a diagnostic value which they do not possess in the other forms of nephritis. Early as the white patches or degenerative changes are they precede and result from still earlier changes in the vessels (silver-wire arteries). Although the silverwire arteries are no doubt ophthalmoscopic evidence of the vascular degeneration, as are also the hæmorrhages and white spots, it does not follow that the vessels necessarily show the white silver-wire streaks before the other lesions are visible.

Of the hæmorrhages which occur in albuminuric retinitis it is not necessary to say much. Similar hæmorrhages may occur in both the exudative and in the degenerative forms, but they are probably produced in different ways in each case. In the latter they are the consequence of the vascular degeneration and are due to the rupture of the diseased arteries in the retina as in other parts of the body; in the former they are generally due to the rupture of over-distended veins consequent on the pinching to which the veins are subjected as they pass through the swollen disc.
Paradoxical as it may seem, it is in the so-called extreme forms of albuminuric retinitis, or, as I should call them, the exudative forms, that the prognosis both in respect of life and in respect of sight is not nearly so grave as it might appear to be, for if the kidney mischief recover, the eye lesion may resolve and the sight may be completely restored. If, as in pregnancy, the cause return, the retinitis may also return, and with each succeeding pregnancy the prognosis in respect of sight of course becomes worse. In respect of life the prognosis is that of the renal disease, and all, I think, that the albuminuric retinitis in these cases does is to show that we have a form of parenchymatous nephritis to deal with of a somewhat unusual severity. The white patches of granular kidney rarely disappear, but they are often present without much defect of sight. The ophthalmoscopic changes in the vessels are important as evidence of an arterial degeneration which is not limited to the eye and it is a visual evidence of the risks to which the patients are subject from the disease of the vessels elsewhere-e.g., in the brain.

I may bring this communication to a conclusion by summing up the facts which I think justify the drawing of a sharp distinction between the two forms of albuminuric retinitis, the degenerative and the exudative. They stand in strong contrast with each other in the following respects :-

1. Of the form of disease with which they are usually associatedthe degenerative with granular kidney, the exudative especially with parenchymatous nephritis.

2. Of their nature and cause, the exudative being inflammatory and probably toxic in origin, the degenerative consequent on vascular changes and more or less mechanical in origin.

3. Of sight, for the exudative, even in the extreme forms, may recover, with little or no defect of sight, but with the degenerative, if there is any impairment of sight, it is usually progressive.

4. Of diagnostic value, the exudative being an interesting byphenomenon of chronic parenchymatous nephritis, an affection the existence of which is obvious enough while in , an ar kidney the distence of which is obvious enough, while in granular kidney the degenerative often ma

5 . Of risk to life, for while in both cases it indicates a grave form of renal disease which may of itself prove fatal, in granular kidney it indicates in addition all those dangers to which arterial disease exposes the patient.

I think, therefore, that the distinction is not only justified by the facts, but that it explains many of the apparent contradictions which are made by different authors.

Wimpole-street, W.

\section{FOUR CASES IN WHICH THE SYMPTOMS AND SIGNS SUGGESTED VOLVULUS OF THE TRANSVERSE COLON.}

Treated BY Rotating the Body Round The Long AXIS WHILE IN THE HoRIzONTAL PostTION.

\section{BY G. H. HUNTER, M.R.C.S.ENG., L.S.A., D.P.H. LOND.}

THE following four cases are of much interest and the rapid relief of symptoms which followed the treatment is very striking, but the evidence of the presence of a volvulus is by no means sufficient to make the diagnosis certain.

CASE 1.-The chief officer of a merchant steamer, aged about 27 years, a small, spare, thin, healthy, and abstemious man, took, according to his own statement, some "French purgative pills" on turning in at night. At about six o'clock on the next morning a message came asking that he should be seen "at once." On entering his cabin he was found to be lying on his back in his berth with both his knees drawn up, his mouth drawn down at the corners, his face ashen grey, his lips livid, and with beads of perspiration rolling down his brow and face. The skin was cold and clammy. He said that he had great pain "in the stomach," pointing especially to the right hypochondrium and the upper part of the right lumbar region. The muscles of the abdominal wall were rigid, but there was no tympanites. He was lying with his right side to the wall of his cabin and was approached from his left, and the left hand was principally used in examination. On palpating the regions named nothing could be made out owing to the muscular resistance. On being asked to inspire and expire deeply he attempted to comply but pain pulled the inspiration up short. He was then asked to turn on to his right side, as it was thought that the tips of the fingers could be pressed in under the ribs in 
that position. He tried to do so, but when he had turned through an angle of about $75^{\circ}$ he fell back on to his back with a sharp cry. He said that the pain was much increased by turning to the right side. A volvulus was diagnosed twisted from right to left and increased in tightness by turning to the right through the loop involved falling by its own weight round its own axis towards the left. To unwrap this the patient was told to turn round three times to the left while lying as straight out as he could. This he did, the first time turning with much pain and difficulty, the second time with less of both, and the third time quite easily. On settling on to his back again the blood returned in a wave over his face and lips and after a transient blush his face regained its normal appearance. On being asked how the pain was he said that it was "gone." The abdomen was lax and he allowed free manipulation, but nothing abnormal was to be discovered. He went on duty half-anhour afterwards. He had never previously had any abdominal trouble, but he said that he "very occasionally required a laxative but not a purge."

CASE 2.-A woman, aged about 60 years, a multipara, who was very fat and who had been previously healthy and abstemious, was suddenly seized with severe pain in the same regions as those mentioned in Case 1 without any obvious cause. She treated herself with hot turpentine fomentations for three or four hours, but without relief. On examination, owing to the extreme obesity of the patient, nothing conld be discovered except great muscular resistance. She was told to turn herself round in bed three times to the left, it having first been found that a half turn to the right increased the pain. She did so, when she expressed herself as being "in heaven." The pain had disappeared. Some weeks afterwards the patient had another attack of the same nature. On this occasion the axial rotation, though it relieved did not entirely remove the pain, which eventually yielded to small doses of opium and hot fomentations. She suffered from constipation and a good deal of flatus was passed, but eventually, in about five days, the bowels acted naturally.

CASE 3.-A girl, aged 12 years, who was strong and had been previously healthy, "was skylarking with her brother and hurt herself." When seen shortly afterwards she was in bed and complained of pain in the same regions as those mentioned in the previous cases. The pain was not severe, but was bad enough to prevent movement. There was not much tenderness on manipulation and no lump was to be felt. The pain and tenderness seemed to be superficial and it was thought that some of the muscular fibres had been torn. Hot turpentine fomentations and rest in bed were ordered and as the child was excited over missing her school attendance a little chloral and bromide were given. The bowels acted every other day. On the tenth day the pain increased suddenly and an urgent message was sent asking for immediate attendance. On being seen the face for the first time looked drawn but flushed. The temperature was $102^{\circ} \mathrm{F}$. and the pulse was 112. On examination a firm oval lump was felt lying across the upper part of the right lumbar region, tympanitic but not very tense. The axial rotation from right to left was practised three times and the lump became quite soft and dull to percussion, but it did not disappear entirely though the pain ceased at once. On the next day the temperature and pulse were normal and there was no pain, but the lump was still tender on palpation though it was much reduced in size. The patient got up on the next day and went to school. Six months afterwards she was quite well and the lump had disappeared.

CASE 4.-A woman, aged 27 years, a multipara, who was stout and who from lack of teeth had been subject to dyspepsia but was otherwise healthy, took a Seidlitz powder during the hot weather of 1898 . She drank it greedily " to get all the fizz." Shortly afterwards she was seized with "severe cramp in the stomach" and "felt inclined to vomi but could not do so." On being seen about four hours afterwards she looked a little flushed, but her condition seemed otherwise to be normal, except that the upper two zones of the abdomen were distended by gas, which could be heard as it rumbled about in the bowels. She had brought up a little flatus once or twice, which relieved the pain in the stomach somewhat, and a little flatus had also passed downwards. An emetic of a pint and a half of warm water with a little mustard was given, which acted promptly and brought up a good deal of gas and sticky mucus. This gave great relief. Half a grain of hydrochlorate of morphia was given by the mouth and another was left to be taken if any nausea should supervene. On the next day the stomach was in its normal state, but a large oval and very tightly distended lump was found lying across the upper part of the right lumbar region, extending about two inches into the umbilical region. The axial rotation as in the other cases removed the obstruction and pain immediately, and when the patient lay back in bed the lump had disappeared. The abdomen was freely examined and nothing abnormal could be felt.

In all these cases the pain was indicated as being most. severe in the upper part of the right lumbar region, about two inches below the tip of the gall-bladder, but in Cases 3 and 4 the obstruction was evidently about the middle of the transverse colon. The practical point in all of the cases except in that of the second attack in Case 2 was the instantaneous and complete relief which was afforded from pain, and which was accompanied in the last two cases by the disappearance practically of the swelling. Finally, what were these cases? The success of the treatment by rotation. strongly suggests the untwisting of a volvulus twisted from. right to left, more especially as in Cases 1 and 2 an initial half turn to the right increased the pain (? by further twisting the pedicle). If this view be adopted axial rotation. in the horizontal position might be employed in cases of sudden and severe pain in the regions which have been mentioned to diagnose the existence of a volvulus. A half turs. first to one side and then to the other, if it increased the pain in one direction and not in the other, would suggest a. volvulus and would point out the direction of the twist, and then rotation in the opposite direction ought to unwrap the volvulus.

Haughley, Suffolk.

\section{THE DETECTION AND ESTIMATION O PHOSPHORIC ACID IN A DROP OF BLOOD.}

Bx WILliam MaCKIE, M.A., M.D. ABerd.

IT has been stated, chiefly, if not exclusively, on the authority of Continental observers, ${ }^{2}$ that the proportion of phosphoric acid in the blood is increased in certain diseases. and diminished in others. These results have been obtained. by operating on large quantities of blood by methods which, on account of their intricacy and the length of time required for their execution, are altogether precluded as general clinical methods. The method of estimating phosphoric: acid now to be described is suggested as an easy, expeditious, and sufficiently accurate method for comparative purposes. It has the additional advantage from a clinical point of view of requiring for its operation such minute quantities of blood as can easily be spared by the feeblest patient. It is colorimetric in principle and depends on the greenish-yellow tint which even very minute traces of phosphoric acid strike with a solution of ammonium molybdate in hydrochloric acid. The ordinary solution of ammonium molybdate in nitric acid, which is used in the chemical laboratory for the separation of phosphoric acid from acid solutions, may be used for the present purpose, but the latter throws down a precipitate much more readily than the hydrochloric acid solution. As the formation of a precipitate naturally vitiates the result the former solution is to be preferred. The colour reaction is accelerated and intensified by the application of heat. In the cold some little time is required for its development. The method may be so arranged that the determinations may be made in warm solutions. As the molybdate solution, however, by itself takes on a very slight colouration on heating I prefer when very minute quantities of phosphoric acid are to be determined to use cold solutions alone. In the cold the colour produced by one part of phosphoric anhydride $\left(\mathrm{P}_{2} \mathrm{O}_{5}\right)$ is distinctly perceptible in 3,000,000 parts of water. After considerable search I have found no reference to the application of ammonium molybdate to the colorimetric estimation of phosphoric acid, so that both the method and the particular application of it to the determination of phosphoric acid in minute quantities of blood appear to be new. The same reagent, it should be noted, strikes a similar colour with arsenic and silicic

1 Freund : Wiener Medicinische Wochenschrift, Band xxxvii., pp. 10 40, 1887; Moraczewski : Zeitschrift fur Physiologische Chemie, Ban xxii., pp. 121-136, 1897; Virchow's Archiv, cxlvi., pp. 424-452, 1896. 